\title{
FITOTECNIA
}

\section{COMPORTAMENTO FENOLÓGICO DE VIDEIRA, CULTIVAR PATRÍCIA EM DIFERENTES ÉPOCAS DE PODA DE FRUTIFICAÇÃO EM GOIÁS ( ${ }^{1}$ )}

\author{
RICARDO PEREIRA DA SILVA $\left({ }^{2}\right)$; GUSTAVO GONDIM DANTAS $\left({ }^{2}\right)$; \\ RONALDO VELOSO NAVES $\left({ }^{3}\right)$; MARCOS GOMES DA CUNHA $\left(\left(^{*}\right)\right.$
}

\begin{abstract}
RESUMO
O experimento foi desenvolvido no município de Silvânia (GO), em pomar comercial de uva 'Patrícia' (IAC 871 - 41) durante o período de fevereiro a outubro de 2003. O objetivo deste trabalho foi avaliar o comportamento fenológico e as características dos cachos e das bagas da cv. Patrícia em diferentes épocas de poda $(13 / 3$, 28/3, $12 / 4$ e 27/4). A duração do ciclo (poda - colheita) foi de 152, 172,185 e 178 dias para as podas realizadas em 13/3, 28/3,12/4 e 27/4 respectivamente. As épocas de podas não afetaram significativamente o tamanho e a forma dos cachos, entretanto, grandes e medianamente compactos com comprimento médio de $20,52 \mathrm{~cm}$. O maior diâmetro de baga foi encontrado na poda realizada em $27 / 4$ com 19,14 mm, padrões considerados adequados para a cultivar. As diferentes épocas de poda não exerceram influência sobre os teores de sólidos solúveis totais, com média de $18,4{ }^{\circ}$ Brix. Todavia, houve variação significativa para a acidez total titulável, evidenciada nas podas de $13 / 3$ e $27 / 4$, respectivamente, com 1,44 e 0,87g de ácido tartárico/100 $\mathrm{mL}$ de mosto de uva. As diferentes épocas de poda afetaram significativamente a relação SST/ATT, sendo a menor relação encontrada na poda realizada em 13/3 com apenas 13,0 e a maior na poda de $27 / 4$ com 21,9 .
\end{abstract}

Palavras chave: fenologia, características físico-químicas, uva de mesa, Vitis vinifera L.

\section{ABSTRACT \\ PHENOLOGYC BEHAVIOR GRAPEVINE, OF CV. PATRÍCIA IN DIFFERENT TIMES OF FRUCTIFICATION PRUNING IN GOIÁS}

The experiment was developed in the council of Silvânia, State of Goiás, in commercial orchard of grape 'Patrícia' (IAC 871 - 41) during the period of February to October of 2003. The objectives of this work were to evaluate the phenologycal behavior and the characteristics of the bunches and berries of Patrícia cultivar in different pruning times (March 13, March 28, April 12 and April 27). Durations of the stage (pruning - harvest) were of 152, 172, 185 and 178 days for the prunings accomplished on March 13, March 28, April 12, and April 27, respectively. The pruning times did not affect the size and the form of

$\left({ }^{1}\right)$ Recebido para publicação em 16/4/04 e aceito em 23/6/06.

( $\left.{ }^{2}\right)$ Mestrando em Produção Vegetal, Escola de Agronomia e Engenharia de Alimentos, Universidade Federal de Goiás. Bolsista do CNPq. E-mail: ricperesilva@hotmail.com; gubam@bol.com.br

$\left({ }^{3}\right)$ Departamento de Horticultura. Universidade Federal de Goiás, Escola de Agronomia e Engenharia de Alimentos, Rodovia Goiânia/Nova Veneza, km 0, Caixa Postal 131, 74001-970 Goiânia (GO) . E-mail: ronaldo@agro.ufg.br.

$\left({ }^{4}\right)$ Departamento de Fitopatologia. Universidade Federal de Goiás, Escola de Agronomia e Engenharia de Alimentos, 74001-970 Goiânia (GO). E-mail: mgc@agro.ufg.br. *Autor correspondente. 


\begin{abstract}
the bunches significantly, however, these became large with length of about $20.52 \mathrm{~cm}$. The largest berry diameter was found in the pruning accomplished on April 27 with $19.14 \mathrm{~mm}$, patterns considered appropriate for cultivation. The different pruning dates did not show influence on total soluble solids, with an average of $18.4^{\circ}$ Brix, however there was no variation for the total acidity titratable, evidenced in the prunings of March 13, and April 27, respectively, with 1.44 and $0.87 \mathrm{~g}$ of tartaric acid $/ 100 \mathrm{~mL}$ of grape juice. The different pruning dates affected significantly the SST / ATT relationship, being the smallest relationship found in the pruning date of March 13 with 13.0 and the largest in the pruning date on April 27 with 21.9 .
\end{abstract}

Key words: phenology, physiochemical characteristics, table grape, Vitis vinifera L.

\section{INTRODUÇÃO}

A expansão da viticultura brasileira tem levado os produtores cada vez mais a se adequarem às novas técnicas e manejo da cultura, sobretudo com uso de tecnologias envolvendo os tratos culturais, evidenciando neste caso a realização de épocas de poda. Estas podem ser determinantes em uma safra, uma vez que é a partir da poda que se inicia o ciclo produtivo da videira. Segundo FERRI (1994), os estudos de comportamento fenológico das variedades estão sendo realizados em várias regiões produtoras e sabese que cada espécie variedade comporta-se de maneira distinta quando submetidas a condições edafoclimáticas diferenciadas.

Empregando-se mais tecnologias (manejo da irrigação, poda, etc.) e dispondo de estudos de melhoramento genético para melhor adaptação das variedades, a Região Nordeste do país vem se destacando na produção de uvas finas de mesa voltadas tanto para o mercado nacional como para o internacional. Assim, tais tecnologias podem ser utilizadas e ou adaptadas em regiões onde há demanda de informações. Assim, faz-se necessário o conhecimento prévio da fenologia de cada cultivar e sua adaptabilidade às regiões.

Leão (1999) relata que o estudo da fenologia é de fundamental importância para o planejamento das atividades a serem realizadas no vinhedo, bem como para a previsão da data de colheita e comercialização. Para Albuquerque e Albuquerque (1982), em climas tropicais semi-áridos, verifica-se na videira comportamento fenológico totalmente distinto daquele das regiões de clima subtropical e temperado, estando condicionada ao controle da irrigação e à época de poda. Pode-se, então, concluir que as condições climáticas influenciam na fenologia e na fisiologia das plantas, conseqüentemente na produção e qualidade dos frutos.

A fenologia visa caracterizar a duração das fases do desenvolvimento da videira em relação ao a mbiente, especialmente às variações climáticas estacionais, servindo para interpretar como as diferentes regiões climáticas interagem com a cultura (Terra et al., 1998). De acordo com LeÃo e Silva (2003), a fenologia varia em função do genótipo e das condições climáticas de cada região produtora ou em uma mesma região devido às variações estacionais do clima ao longo do ano. Também fornece informações ao viticultor para o conhecimento antecipado das prováveis datas de colheita, indicando ainda o potencial climático das regióes para o cultivo e a produção de uva (PEDro Junior et al., 1993).

Para o Estado de Goiás, as informações a respeito do comportamento fenológico e produtivo de videiras ainda não foram realizados, apesar da existência de parreirais implantados nessa região. Com isso, técnicos e produtores serão beneficiados com as informações deste estudo, podendo ser usadas para o desenvolvimento da viticultura no Estado. Para LEÃo (1999), em condições de clima tropical, como as predominantes na região, a videira vegeta continuamente, não apresentando fase de repouso hibernal. A data de poda passa a ser a referência para o início do ciclo fenológico.

Este trabalho teve como objetivo avaliar o comportamento fenológico da videira, cultivar Patrícia, em diferentes épocas de poda e também quantificar os caracteres relacionados aos cachos e às características físico-químicas das bagas.

\section{MATERIAL E MÉTODOS}

O experimento foi conduzido em pomar comercial localizado no município de Silvânia, Estado de Goiás, latitude $16^{\circ} 43^{\prime} 22^{\prime \prime} \mathrm{S}$, longitude de $48^{\circ} 50^{\prime}$ $08^{\prime \prime} \mathrm{W}$ e altitude de $900 \mathrm{~m}$. De acordo com o sistema proposto por Köppen, o clima da região é classificado como Cwa, temperado com inverno seco e ameno e verão quente e chuvoso. Para a coleta de temperaturas na área do experimento foi usado um termohigrômetro modelo HI-208 com resolução de $0,1{ }^{\circ} \mathrm{C}$ devidamente instalado em um abrigo meteorológico. As temperaturas e precipitações médias mensais para o município de Silvânia estão na figura 1. 


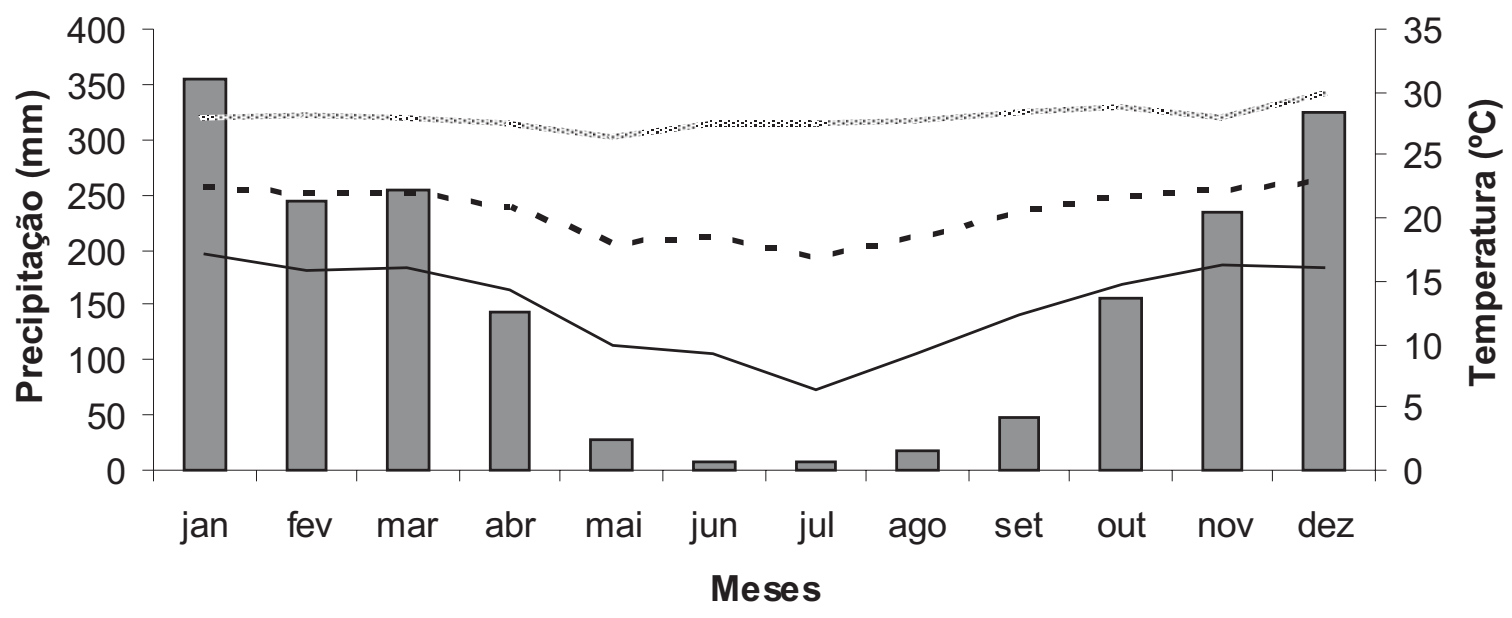

Precipitação

T. mín. - - - - T. média

Figura 1. Médias mensais de temperatura e precipitação pluviométrica, referente ao ano de 2003, município de Silvânia (GO) Fonte: Estação Meteorológica Floresta Nacional de Silvânia (GO), 2003.

O delineamento estatístico empregado foi o de blocos casualizados com quatro tratamentos e cinco repetições; os tratamentos foram as épocas de poda e cada parcela constituída de quatro plantas, duas úteis. As podas foram realizadas nas seguintes datas: 13 de março, 28 de março, 12 de abril e 27 de abril de 2003. Os dados coletados foram submetidos à análise de variância e, em caso de significância, efetuou-se o teste de Tukey para comparação de médias.

$\mathrm{O}$ vinhedo com 5 anos de idade, enxertado sobre IAC 572 'Jales' foi conduzido em sistema de latada com espaçamento de $3 \times 2,5 \mathrm{~m}$ e irrigado com microaspersão sob copa. O sistema de poda adotado foi de poda de produção mista, com oito gemas nas varas e até duas nos esporões. Logo após a poda foi realizada a aplicação da cianamida hidrogenada $\left(\right.$ Dormex ${ }^{\circledR}$ ), na concentração de $7 \%$. Os tratos culturais da videira como adubação, operações de poda verde e tratamentos fitossanitários foram executados segundo recomendações preconizadas por TERrA et al. (1998).

A partir de cada poda, realizaram-se três avaliações semanais em plantas previamente marcadas, para determinar a duração dos estádios fenológicos. Para tal, foram feitas avaliações visuais registrando as datas das principais fases e subfases, no momento em que completavam $50 \%$ de iniciados. As determinações dos estádios fenológicos foram baseadas na classificação de EICHHORN e LORENZ (1984) da seguinte forma: da poda até gemas inchadas; de gemas inchadas ao início da brotação; da brotação ao aparecimento da inflorescência; do aparecimento da inflorescência ao início do florescimento; do início do florescimento ao florescimento pleno; do pleno florescimento ao início da frutificação; do início da frutificação à fase de "chumbinho"; da fase de "chumbinho à fase de "ervilha"; da fase de "ervilha" ao início da compactação do cacho; da compactação do cacho ao início da maturação; do início da maturação até a colheita.

Para as avaliações do desenvolvimento dos cachos foram escolhidos, aleatoriamente, cinco cachos por planta e avaliados quinzenalmente até o fim da colheita. A partir da fase de "chumbinho" iniciaramse as medições do comprimento $(\mathrm{cm})$ e largura $(\mathrm{cm})$ dos cachos. No momento da colheita, quando as uvas atingiram o teor de sólidos solúveis totais maior ou igual $17^{\circ}$ Brix, também foram determinados: forma, compacidade e massa de cinco cachos.

A partir do início da maturação das bagas com o auxílio de refratômetro manual avaliaram-se a cada sete dias os teores de sólidos solúveis totais (SST). Após a colheita procedeu-se as seguintes avaliações: massa de 10 bagas $(\mathrm{g})$, comprimento $(\mathrm{mm})$, diâmetro $(\mathrm{mm})$, número de bagas por cacho. A acidez total titulável (ATT) e a relação SST / ATT foram realizadas de acordo com métodos estabelecidos pelo INSTITUTO Adolfo Lutz (1985). 


\section{RESULTADOS E DISCUSSÃO}

\subsection{Fases fenológicas}

\section{Período da poda ao início da brotação}

Observando-se a tabela 1, nota-se certa uniformidade entre os tratamentos, não havendo variação maior do que três dias entre a poda e o início da brotação. De acordo com Boliani (1994), em estudos realizados em Jales (SP), conclui-se que temperaturas entre $25{ }^{\circ} \mathrm{C}$ e $30{ }^{\circ} \mathrm{C}$ são amplamente favoráveis ao desenvolvimento das gemas. Através dos dados obtidos pode-se, então, concluir que temperaturas elevadas no início de abril com médias de $25^{\circ} \mathrm{C}$, logo após a terceira poda contribuíram para a aceleração do início da brotação. No fim de abril, época da realização da quarta poda, ao contrário do início do mês, ocorreram temperaturas baixas, com médias de $18{ }^{\circ} \mathrm{C}$, resultando em atraso no início da brotação.

\section{Período da poda ao início do florescimento}

Conforme a tabela 1 , o número de dias entre a poda e o início do florescimento para a cultivar Patrícia variou no máximo cinco dias, compreendidos entre 40 e 45 dias. A maior variação foi observada na poda de $27 / 4$. Conclui-se que, de modo geral, quanto maior o atraso da época de poda, maior foi o número de dias para iniciar o florescimento. Em contrapartida, KISHINO (1981) observou que para as podas realizadas no inverno, o período obtido para a cv. Itália compreendido entre a poda e o florescimento foi de 52 dias, porém para as podas tardias o período variou entre 33 e 35 dias. Por esses resultados verifica-se que as variações climáticas ocorridas interferem no comportamento fenológico das cultivares.

\section{Período da poda ao início da frutificação}

Os dias necessários para completar esse período foram de 53, 53, 56 e 59 para as podas de 13 /
$3,28 / 3,12 / 4$ e $27 / 4$ respectivamente. A poda realizada em $27 / 4$ foi a que apresentou o período mais longo para o início a frutificação (Tabela 1). Pelas análises desses dados observa-se que as diferentes épocas de poda podem elevar em poucos dias o período existente entre a poda e o início da frutificação.

\section{Período da poda ao início da maturação}

Nesse período, quando ocorreu a maior variação no ciclo da videira para as diferentes épocas de poda (Tabela 1), observaram-se os seguintes dados: poda de 13/3 - 104 dias; poda de 18/03 - 109 dias; poda de $12 / 4$ - 111 dias e poda de $27 / 4$ foram necessários 121 dias.

O atraso ou a antecipação na maturação dos cachos promovida pelas diferentes épocas de podas aplicadas à cultivar podem ser interessantes para o viticultor, uma vez que, permite-se o escalonamento da colheita e conseqüente comercialização dos frutos, em períodos de menor oferta, quando os preços estão mais altos. Outro aspecto interessante inerente à antecipação da maturação seria o de quanto maior for o período em que os frutos permaneçam no parreiral, maior será sua vulnerabilidade à ocorrência de doenças provenientes de condições favoráveis, oriundas principalmente de períodos chuvosos em meses próximos às épocas de colheita e comercialização dos frutos.

\section{Período da poda à colheita}

As colheitas foram realizadas aos 152,172 , 185 e 178 dias após, as podas de 13/3, 28/3, 12/4 e 27/4 respectivamente, com média de 172 dias (Tabela 1). Foram necessários 185 dias para a videira completar seu ciclo produtivo na poda de 12/4. Em contrapartida na poda de $13 / 3$, o período entre a poda e a colheita foi de apenas 152 dias. Fato devido às temperaturas elevadas ocorridas em março, logo após a execução da poda de frutificação.

Tabela 1. Duração em dias, para as fases do ciclo fenológico da cultivar Patrícia, a partir de diferentes épocas de poda em Silvânia (GO), 2003

\begin{tabular}{lcccc}
\hline \multirow{2}{*}{ Fase Fenológica } & \multicolumn{3}{c}{ Época de poda } \\
\cline { 2 - 5 } & $13 / 3$ & $28 / 3$ & $12 / 4$ & 11 \\
Início da brotação & 13 & 13 & 43 & 14 \\
Início do florescimento & 40 & 40 & 56 & 45 \\
Início da frutificação & 53 & 53 & 111 & 121 \\
Início de maturação & 104 & 109 & 185 & 178 \\
Início da colheita & 152 & 172 & 59 & \\
\hline
\end{tabular}


Esses resultados estão próximos aos valores obtidos por Pereira e SANTOS Neto (1973) que relatam em 150 dias para a cultivar Patrícia completar seu ciclo produtivo, no Estado de São Paulo. Entretanto, para o norte do Estado de Minas Gerais, na Fazenda Experimental de Mocambinho/EPAMIG, no município de Jaíba, Rodrigues e Miranda (1997) observaram que o período de poda até a colheita variou de 120 a 130 dias. Em contrapartida, Choudhury (2000) cita um período que varia de 117 a 125 dias em estudo realizado no Nordeste brasileiro. Todos esses resultados confirmam que as videiras cultivadas em locais distintos comportam-se de maneira diferente, principalmente em relação à fenologia de cada cultivar.

Esse fato também foi comprovado por LEÃo e Silva (2003), em conclusão do trabalho realizado com variedades de uvas sem sementes no Vale do São Francisco, onde as condições climáticas prevalecentes nas diferentes épocas de poda estudadas exerceram influência sobre a duração dos estádios fenológicos de todas as variedades.

\subsection{Subfases}

Com relação às subfases, as diferenças entre os tratamentos não foram expressivas (Tabela 2), com algumas exceções: da brotação até o aparecimento da inflorescência que na poda de $13 / 3$ foi de cinco dias de duração e na poda de $27 / 4$, de 9 dias. Para o período de compactação do cacho até o início da maturação foram necessários 15 e 22 dias nas podas de $13 / 3$ e $27 / 4$ respectivamente, apresentando uma diferença de sete dias. Em relação à subfase de início da maturação à colheita, a maior diferença foi de 48 dias para a poda de $13 / 3$ enquanto que na poda de 12/4 foram necessários 74 dias.

Conforme a tabela 2, a poda realizada em 12 de abril retardou a maturação da uva em 26 dias comparado com a poda de 13 de março. Todavia, na poda de 27 de abril ocorreram apenas 9 dias de diferença para aquela realizada em 13 de março e antecipou a maturação em 17 dias em relação à poda de 12 de abril. Enquanto o período de início da maturação até a colheita para a poda de 12 de abril foi de 74 dias, para a poda realizada no dia 27 de abril durou apenas 57 dias. Segundo relatos de Pires e Pommer (2003), esses valores estão acima dos padrões estabelecidos para a cultivar, no qual citam de 20 a 50 dias para completar o período da maturação.

Para as outras subfases não ocorreram variações no número de dias observados; o máximo foi de 4 dias entre as épocas de poda.

\subsection{Desenvolvimento dos cachos}

Na análise de variância não houve diferença estatística entre as épocas de poda para o comprimento do cacho, sendo a variação dos dados obtidos entre 20,18 e 20,85 cm (Tabela 3). Esses valores estão de acordo com os dados encontrados por Albuquerque (2002) que obteve cachos de 18 a $22 \mathrm{~cm}$, classificando-os como cachos grandes segundo escala proposta por GALET (1985).

Tabela 2. Número de dias compreendidos entre cada fase fenológica da cultivar Patrícia, em diferentes épocas de poda em Silvânia (GO), 2003

\begin{tabular}{|c|c|c|c|c|}
\hline \multirow{2}{*}{ Fase fenológica da videira } & \multicolumn{4}{|c|}{ Época de poda } \\
\hline & $13 / 3$ & $28 / 3$ & $12 / 4$ & $27 / 4$ \\
\hline 1. Poda até gemas inchadas & 6 & 7 & 7 & 9 \\
\hline 2. Gemas inchadas ao início da brotação & 7 & 6 & 4 & 5 \\
\hline 3. Brotação ao aparecimento da inflorescência & 5 & 6 & 7 & 9 \\
\hline 4. Aparecimento da inflorescência ao início do florescimento & 22 & 21 & 25 & 22 \\
\hline 5. Início do florescimento ao florescimento pleno & 7 & 7 & 9 & 7 \\
\hline 6. Pleno florescimento ao início da frutificação & 6 & 6 & 4 & 7 \\
\hline 7. Início da frutificação à fase de "chumbinho" & 5 & 6 & 4 & 6 \\
\hline 8. Fase de "chumbinho à fase de "ervilha" & 8 & 7 & 7 & 9 \\
\hline 9. Fase de "ervilha" ao início da compactação do cacho & 23 & 24 & 23 & 25 \\
\hline 10. Compactação do cacho ao início da maturação & 15 & 19 & 21 & 22 \\
\hline 11. Início da maturação até a colheita & 48 & 63 & 74 & 57 \\
\hline Ciclo total (poda - colheita) & 152 & 172 & 185 & 178 \\
\hline
\end{tabular}


Em contrapartida, valores superiores foram encontrados por TERRA et al. (1984), cujo comprimento médio foi de $23,3 \mathrm{~cm}$. Estudando a caracterização agronômica e fenológica de cultivares do gênero Vitis spp. FERRI (1994) observou para a cultivar Patrícia apenas $16,0 \mathrm{~cm}$ de comprimento do cacho, média inferior quando comparada à encontrada neste trabalho (Tabela 3). Para a largura do cacho, na análise de variância não houve diferenças estatísticas significativas para os valores finais. O valor médio foi de $10,67 \mathrm{~cm}$, superior ao encontrado por FERRI (1994) que anotou para essa característica 10,10 cm de comprimento (Tabela 3).

Para os dados referentes ao número de bagas por cacho, observou-se efeito estatístico significativo nas diferentes épocas de poda. As podas de 28/3, $12 / 4$ e $27 / 4$ proporcionaram, respectivamente, médias de 93,70; 102,50 e 93,72 bagas/cacho e 119 para a poda de 13/3 (Tabela 3). Em escala estabelecida por Albuquerque (2002), os valores para o número de bagas/cacho estão entre 80 e 100, classificando-os como excelentes a bons respectivamente. Somente os números de bagas encontrados nas podas de $28 / 3$ e $27 / 4$ estão de acordo com a escala proposta pelo autor.

O número excessivo de bagas nos cachos (poda $28 / 3=119,60)$ deve-se ao fato de não ser usada a técnica de raleio de bagas nessa cultivar de uva de mesa. Esta é uma prática onerosa e que aumenta muito o custo de produção da uva, necessitando de mão-de-obra qualificada, o que não ocorre na região devido ao número pequeno de áreas com cultivo de uva fina de mesa.

Na tabela 3 pode-se observar a massa média dos cachos. Pela análise estatística também se observou efeito significativo entre os tratamentos. Esses resultados ainda estão abaixo daqueles observados por Pereira e Santos Neto (1973) com 400-600 g; 595 g (Ferri, 1994), ambos no Estado de São Paulo e por Albuquerque (2002) com $567 \mathrm{~g}$ de massa média no município de Juazeiro (BA). Entretanto, observou-se médias superiores às encontradas por Rodrigues e Miranda (1997) que relataram massas médias de 179,5 g em Minas Gerais, e também para os valores encontrados por MARTINs et al. (1981), que testando cinco portaenxertos para a cultivar Patrícia (IAC 871-41), em Jundiaí (SP), obtiveram massas médias de 288-336 g utilizando o IAC 313 como porta-enxerto.

Os cachos da cv. Patrícia foram classificados como grandes, medianamente compactos e com formatos cônicos simples e alados a cilíndricos simples. Esses resultados são semelhantes aos encontrados por FERRI (1994), que caracterizou os cachos como compactos e cônicos alados.

Tabela 3. Características físicas e químicas dos cachos e das bagas da cultivar Patrícia, em diferentes épocas de poda em Silvânia (GO), 2003

\begin{tabular}{|c|c|c|c|c|c|c|}
\hline \multirow{2}{*}{ Variáveis } & \multicolumn{4}{|c|}{ Épocas de poda } & \multirow{2}{*}{$\begin{array}{c}\text { C.V. } \\
(\%)\end{array}$} & \multirow{2}{*}{$\begin{array}{c}\text { Teste } \\
\text { F }\end{array}$} \\
\hline & $13 / 3$ & $28 / 3$ & $12 / 4$ & $27 / 4$ & & \\
\hline Comprimento do cacho $(\mathrm{cm})$ & $20,85 \mathrm{a}$ & $20,22 \mathrm{a}$ & 20,18 a & $20,85 \mathrm{a}$ & 12,95 & $0,68^{\text {ns }}$ \\
\hline Largura do cacho $(\mathrm{cm})$ & $10,69 \mathrm{a}$ & $10,45 \mathrm{a}$ & $10,97 \mathrm{a}$ & $10,52 \mathrm{a}$ & 13,95 & $1,18^{\mathrm{ns}}$ \\
\hline Número de bagas/cacho & $119,60 \mathrm{a}$ & $93,70 \mathrm{~b}$ & $102,50 \mathrm{~b}$ & $93,72 \mathrm{~b}$ & 25,13 & $10,49^{* *}$ \\
\hline Peso de 5 cachos $(\mathrm{g})$ & $2250 \mathrm{a}$ & 1723 a & 1825 a & 1902 a & 23,95 & $2,22^{\text {ns }}$ \\
\hline Peso de 10 bagas (g) & 44,55 a & 44,30 a & 43,83 a & 48,86 a & 13,99 & $1,36^{\mathrm{ns}}$ \\
\hline Comprimento bagas (mm) & $20,83 \mathrm{ab}$ & $20,14 \mathrm{~b}$ & $21,94 \mathrm{ab}$ & 22,41 a & 17,73 & $3,65^{*}$ \\
\hline Diâmetro de bagas (mm) & 17,70 a & 17,46 a & 17,60 a & 19,14 a & 7,70 & $15,93^{* *}$ \\
\hline Sólidos solúveis totais - SST ${ }^{(1)}$ & 18,81 a & 18,79 a & $17,22 \mathrm{a}$ & 18,87 a & 6,02 & $2,61^{\mathrm{ns}}$ \\
\hline Acidez total titulável - $\mathrm{ATT}^{(2)}$ & $1,44 \mathrm{a}$ & $1,09 \mathrm{~b}$ & $0,89 \mathrm{c}$ & $0,87 \mathrm{c}$ & 7,23 & $43,75^{* *}$ \\
\hline Relação SST / ATT & $13,06 \mathrm{c}$ & $17,23 \mathrm{~b}$ & $19,35 \mathrm{ab}$ & $21,70 \mathrm{a}$ & 13,10 & $12,75^{* *}$ \\
\hline
\end{tabular}

Médias seguidas pela mesma letra nas linhas não diferem estatisticamente entre si pelo teste de Tukey.

*; **: significativo a $5 \%$ e a $1 \%$ de probabilidade respectivamente.

$\left.{ }^{1}\right)$ Expressos em ${ }^{\circ}$ Brix; ${ }^{(2)}$ Expressos em gramas de ácido tartárico/100mL do mosto da uva. 


\subsection{Características das bagas}

\section{Características físicas}

$\mathrm{Na}$ análise de variância para o teste $\mathrm{F}$ houve efeito significativo para os valores do comprimento das bagas, ressaltando a diferença entre as podas de $28 / 3$ e $27 / 4$ com médias de 20,14 e $22,41 \mathrm{~mm}$. Para o diâmetro das bagas, a poda de $27 / 4$ foi a única que diferiu significativamente, com média de 19,14 mm de diâmetro (Tabela 3). Esses resultados são similares aos encontrados por Rodrigues e Miranda (1997), que obtiveram valores de 19,0 mm de diâmetro, utilizando duas podas de produção por ano. Entretanto, são inferiores aos encontrados por FERRI (1994) que constatou para o comprimento e diâmetro das bagas respectivamente, 28,2 e $20,2 \mathrm{~mm}$. Sobretudo, os diâmetros de bagas aqui encontrados são classificados como médios de acordo com escala estabelecida para a cultivar. Patrícia descrita por Leão e Grangeiro (2002).

Não houve diferença estatística para o peso médio das bagas (massa de 10 bagas). Em trabalhos realizados observaram-se diversos valores para esse item, um deles TERRA et al. (1984) encontraram 6,60 g em Campinas (SP), utilizando plantas que receberam podas em agosto. FERRI (1994) observou 5,68 g para a massa da baga, valor superior aos dados observados neste trabalho que foi de apenas $4,5 \mathrm{~g} / \mathrm{baga}$. Entretanto, são classificados como grandes em escala descrita por GALET (1985).

\section{Características químicas}

A média para a poda realizada em27 de abril foi de $18,87^{\circ}$ Brix, inferior aos valores mencionados por Santos Neto (1976) e Terra et al. (1984) de $20^{\circ}$ Brix (Tabela 3). Acima dos valores encontrados por Rodrigues e Miranda (1997) de 17,1 ${ }^{\circ}$ Brix de média com duas podas de produção anuais e ainda superiores a valores descritos por MARTINS et al. (1981) que obtiveram média de $16,70{ }^{\circ}$ Brix para uvas cultivadas no interior de São Paulo entre 1975 e 1980. Por esses resultados verifica-se que o teor de sólidos solúveis totais da cv. Patrícia pode sofrer influência quando submetido a condições climáticas distintas.

Ana tabela 3 nota-se diferença estatística entre os tratamentos para a relação entre SST/ATT. As maiores relações existentes foram observadas nas podas de $12 / 4$ e $27 / 4$ com os respectivos valores de 19,35 e 21,70 , adequados ao paladar segundo Gorgatti Netto et al. (1993), enquanto nas podas de $13 / 3$ e $28 / 3$, com médias de 13,08 e 17,27 , são considerados inadequados segundo o mesmo autor.

Para a acidez total titulável, observou-se diferença estatística entre os tratamentos (Tabela 3).
As podas de $12 / 4$ e $27 / 4$ obtiveram médias inferiores, já a poda de 13/3 com 1,44g de ácido tartárico/100 $\mathrm{mL}$ de mosto foi superior aos demais. Assim, plantas podadas em $13 / 3$ e 28/3 deram origem a frutos mais ácidos do que os produzidos após as podas realizadas em $12 / 4$ e $27 / 4$. Temperaturas baixas e dias com menor insolação observados durante o período de maturação da poda de 13/3 (fim de junho até início de agosto), provavelmente contribuíram para a ocorrência de frutos com elevada acidez. Essa poda deu origem à colheita mais precoce, a qual foi realizada no mês mais frio em ralação as demais.

\section{CONCLUSÃO}

1. As diferentes épocas de poda, em $13 / 3,28 /$ 3, 12/4 e 27/4 de 2003, exerceram influência sobre o comportamento fenológico para a cultivar Patrícia; diminuindo o ciclo para 152 dias na poda de 13/3.

2. Os valores de acidez total titulável (ATT) só foram adequados nas duas últimas épocas de poda. Na relação SST / ATT houve melhores valores para a comercialização somente para a última época de poda. As diferentes épocas de poda não tiveram influencia sobre os sólidos solúveis totais (SST), contudo esses valores são adequados para o consumo da cultivar Patrícia para a região.

\section{AGRADECIMENTOS}

Agradecimento especial à Fazenda Bom Jardim e aos funcionários pela concessão da área; à Universidade Federal de Goiás e a Escola de Agronomia e Engenharia de Alimentos, por conceder mais uma oportunidade de aprendizado; ao $\mathrm{CNPq}$ pela concessão da bolsa e à FUNAPE pelo apoio financeiro.

\section{REFERÊNCIAS}

AlbuQuerQue, T. C. S; AlbuQUERQUE, J. A. S. Comportamento de dez cultivares de videira na região do submédio São Francisco. Petrolina-PE: EMBRAPA - CPATSA, 1982. 20 p.

ALBUQUERQUE, T. C. S. de. Avaliação de genótipos apirênicos de videira no semi-árido brasileiro. In: QUEIROZ, M. A. de; GOEDERT, C. O; RAMOS, S.R.R. (Ed.). Recursos genéticos e melhoramento de plantas para o Nordeste brasileiro (on line). Versão 1.0. Petrolina, PE: Embrapa Semi-Árido/Brasília: Embrapa Recursos Genéticos e Biotecnologia, 1999. Disponível em: < http:/ / www.cpatsa.embrapa.br > Acesso em: maio de 2002. 
BOLIANI, A. C. Avaliação fenológica de videira (Vitis vinifera) cv. Itália e Rubi na região Oeste do Estado de São Paulo. 1994. 188 f. Tese (Doutorado em Produção Vegetal). Faculdade de Ciências Agrárias e Veterinárias, Universidade Estadual Paulista, Jaboticabal, 1994.

CHOUDHURY, M. M. Colheita, manuseio pós-colheita e qualidade mercadológica de uvas de mesa. In: LEÃO, P. C. S.; SOARES J. M. A Viticultura no semi-árido brasileiro. Petrolina: Embrapa Semi-árido, 2000. p. 347-360.

EICHHORN, K.W.; LORENZ, D.H. Phaenologische Entwicklungsstadien der Rede. European and Mediterranean Plant Protection Organization, Paris, v. 14, n. 2, p. 295-298, 1984.

FERRI, C. P. Caracterização agronômica e fenológica de cultivares de videira (Vitis spp) mantidos no Instituto Agronômico, Campinas, SP. 1994. 89 f. Dissertação (Mestrado). Escola Superior de Agricultura "Luiz de Quieroz", Universidade de São Paulo, Piraciacaba, 1994.

GALET, P. Précis d'ampelographie pratique. 5. a ed. Montpellier: C. Dehan, 1985. 256 p.

GORGATTI NETTO, A.; GAYET, J. P.; BLEINHOT, E. W.; MATALLO, M.; GARCIA, H.; GARCIA, A. E.; ARDITO, E. F. G.; BORDIN, M. Uva para exportação: Procedimentos de colheita e pós-colheita. Brasília: EMBRAPA-SPI-FRUPEX, 1993. 40 p. il. (Série de publicações técnicas, FRUPEX, 2)

INSTITUTO ADOLFO LUTZ. Normas analíticas do Instituto Adolfo Lutz. Métodos químicos e físicos para a análise de alimentos. 3. ed. São Paulo: Instituto Adolfo Lutz. v.1, 1985. 371p.

LEÃO, P. C. S. Avaliação do comportamento fenológico e produtivo de seis cultivares de uva sem sementes no Vale do Rio São Francisco. 1999. 120 f. Dissertação (Mestrado). Faculdade de Ciências Agrárias e Veterinárias, Universidade Estadual Paulista, Jaboticabal, 1999.

LEÃO, P. C. S. de; GRANGEIRO, L. C. Avaliação de genótipos apirênicos de videira no semi-árido brasileiro. In: QUEIROZ, M. A.; GOEDERT, C. O; RAMOS, S.R.R. (Ed.). Recursos genéticos e melhoramento de plantas para o Nordeste brasileiro (on line). Versão 1.0. Petrolina, PE: Embrapa Semi-Árido/Brasília: Embrapa Recursos Genéticos e Biotecnologia,1999. Livro eletrônico. Disponível em: < http:/ / www.cpatsa.embrapa.br > Acesso em: maio de 2002.
LEÃO, P. C. S. de; SILVA, E. E. G. Caracterização fenológica e requerimentos térmicos de variedades de uvas sem sementes no vale do São Francisco. Revista Brasileira de Fruticultura, Jaboticabal, v. 25, n.3, p. 458-460, 2003.

MARTINS, F. P.; SCARANARI, H. J.; RIBEIRO, I. J. A.; TERRA, M .M.; IGUE, T.; PEREIRA, F. M. Valor comparativo de cinco porta-enxertos para a cultivar Patrícia (IAC 871-41). In: CONGRESSO BRASILEIRO DE FRUTICULTURA, 6, 1981, Recife. Anais... Recife: SBF, 1981. v. 4, p.1300-1310.

PEDRO JÚNIOR, M. J.; SENTELHAS, P. C.; POMMER, C. V.; MARTINS, F. P.; GALLO, P. B.; SANTOS, R. R. BOVI, V.; SABINO, J. C. Caracterização fenológica da videira 'Niágara Rosada' em diferentes regiões paulistas. Bragantia, Campinas, v. 52, n. 1, p. 153-160, 1993.

PEREIRA, F. M.; SANTOS NETO J. R. A. Patrícia (IAC 871-41): novo cultivar de uvas para mesa. In: CONGRESSO BRASILEIRO DE FRUTICULTURA, 2., 1973, Viçosa. Anais... Viçosa: SBF, 1973. v. 2, p. 629-633.

PIRES, E. J. P.; POMMER, C. V. Fisiologia da Videira. In: POMMER, C. V. (Ed.) Uva: Tecnologia de produção, póscolheita, mercado. Porto Alegre: Cinco Continentes, 2003. p. 250-294.

ROBERTO, S. R.; YAMASHITA, F.; KANAI, H. T.; YANO M. Y.; SAZANO, E. M.; GENTA, W. Antecipação da maturação da uva 'Rubi' produzida fora de época no noroeste do estado do Paraná. Comunicação científica. Revista Brasileira de Fruticultura, Jaboticabal, v. 24, n. 3, p. 780-782, 2002.

RODRIGUES, A. G.; MIRANDA, F. R.; Comportamento de cultivares de videira no Norte de Minas Gerais Brasil. Actas de Horticultura. Vol. 18 - II Congresso Iberoamericano e III Congresso Ibérico de Ciências Hortícolas 11-15 de Março, 1997, Vilamoura, Portugal.

SANTOS NETO, J. R. A. Patrícia e Piratininga, variedades de uvas finas de mesa para climas tropicais. Bragantia, Campinas, 35: CXIX-CXXIII, 1976. (Nota, 24)

TERRA, M. M.; PIRES, E. J.; RIBEIRO, I. J. A.; PASSOS, I. R. da. S. Patrícia Branca: mutação somática na videira cultivar (IAC 871-41). Bragantia, Campinas, v. 43, n. 1, p. 267-270, 1984.

TERRA, M. M.; PIRES, E. J. P.; NOGUEIRA, N. A. M.; POMMER, $C$. V. Tecnologia para produção de uva Itália na região noroeste do Estado de São Paulo. Campinas: CATI. 1998. 81p. (Boletim Técnico, 97) 